\section{Effects of irrelevant colors on reading of color names: A controlled replication of the "reversed Stroop" effect}

\author{
FREDERICK N. DYER and LAURENCE J. SEVERANCE* \\ U.S. Army Medical Research Laboratory, Ft. Knox, Ky. 40121
}

Gumenik \& Glass (1970) claimed to have shown a reversed form of Stroop interference in which implicit naming responses to irrelevant colors delayed the reading of color words combined with the colors. In their study, a legibility reduction that did not affect color visibility was interpreted as increasing this interference from color naming to the "weakened" reading response. However, their results could have been only the result of lower legibility for the colored words compared to the control black words. The legibility reduction would be expected to increase any initial legibility difference between colored and black words. In the present study, a neutral word condition and a reduced legibility control condition were included, and evidence was obtained for a bona fide "reversed interference" that was not the result of legibility differences or naming practice. The results were discussed in terms of a symmetrical failure of selective attention to focus on either the color or word analyzer.

In the Stroop color-word test (Stroop, 1935), the time to name colors is delayed when the color patches are shaped to spell incongruent color names. Since the words interfere with naming of the colors on this interference card, it is logical to expect that word reading would be delayed if the word were to become the relevant aspect and the color the irrelevant aspect of these "dual" stimuli. Stroop himself explored the effect of irrelevant colors on reading color names but found that such word reading was delayed only $6 \%$ in comparison to reading of the same color names from a card on which they were printed in black. This delay is sufficiently small that it could result from reduced word legibility because of the reduced luminance contrast of the colored words against their white background and/or from blurring of different colors resulting from the chromatic aberration of the eye. Stroop did show that a great amount of color-naming practice caused interference to word reading when words were read on the interference card immediately following this practice. Time for such reading was nearly twice that required for reading words on the card where they were printed in black, indicating a substantial increase in interference relative to the earlier $6 \%$ increment. However, on a second trial, times to read words on the interference card were almost back to normal. This illustrates the relative weakness and perhaps artifactual nature of this "reversed Stroop interference" compared to the interference of irrelevant words to color naming,

*The authors wish to thank Dennis $M$. Buck, who collected the experimental data. which remains high despite extensive practice (Stroop, 1935; Jensen \& Rohwer, 1966).

Gumenik \& Glass (1970) "weakened" the word-reading response by a procedure that reduced legibility without changing the visibility of the colors. They studied the effect of this weakening of the reading response on both normal and "reversed" Stroop interference. As expected, this greatly reduced the interference of irrelevant words to color naming. In addition, the authors claimed to have increased "reversed" interference by this manipulation, arguing that the greater effect found on word reading when the legibility manipulation was applied to the card of words in color as opposed to the effect when it was applied to the black words was a result of increased competition from the naming response to the weakened reading response. However, the response competition in the normal Stroop task may only result because attention is not able to focus on the color and exclude the word. It may be entirely possible to focus on the word and exclude the color. If this were the case, reducing word legibility would slow word reading but it would not make it more susceptible to interference from the color. The results of Gumenik and Glass would, of course, require another explanation, but such an explanation is readily available. It is the one suggested earlier to account for the $6 \%$ increase in word reading time on the interference card that Stroop (1935) found. Reduced luminance contrast between colored words and their white background would reduce word legibility in comparison to black words (Blackwell,
1946). A further legibility reduction would be expected from the requirement for different ocular accommodation to focus different colors. It has been found in studies of legibility that, when a number of factors that impair legibility are presented together, the effect is greater than the sum of the effects when each is presented alone (Crook, Harker, Hoffman, \& Kennedy, 1949). Because of the initial legibility difference between colored and black words, it would be expected that masking of the words with a series of opaque white diagonal lines, as Gumenik and Glass did, would produce a greater reduction of legibility of the colored words than it would the black words. Thus, differential legibility alone could account for the Gumenik and Glass "reversed interference."

The purpose of the present study was to replicate the word-reading portions of the Gumenik \& Glass (1970) study with additional controls that would allow differentiation between a response competition explanation and a differential legibility explanation of their finding that the legibility-reduction mask slowed word reading more when applied to the interference card than it did when applied to the black word card. The major difference was the inclusion of a condition with neutral words. The reading of these would not be as susceptible to interference from color name responses as would words denoting colors. This assumption is predicated on the finding that interference to color naming from irrelevant words is much less when the reading responses to the irrelevant words differ from the set of naming responses (Klein, 1964). If the effect is strictly due to legibility differences between colored and black words, the reading of noncolor related words should be affected as strongly as the reading of color names by the mask conditions. On the other hand, if different results appear for the two classes of words when the mask is placed over the color card, with longer reading times for the color words, then the conclusions of Gumenik and Glass would be supported. Another control included in the present study was a substitution of shades of gray for the black control reading card. This would eliminate, or at least reduce, the luminance-contrast source of legibility difference for the noncolor comparison card. This would keep word-reading times approximately equal for the masked control and masked color cards, at least in the neutral word condition. One additional difference between the present study and the Gumenik and 
Table 1

Average Word Reading Times (Seconds) at Each Session for the Eight Conditions of the Experiment and the Differences Between Reading Times for the Colored (Interference) and Achromatic (Control) Plates

\begin{tabular}{|c|c|c|c|c|c|c|c|c|}
\hline & \multicolumn{4}{|c|}{ Session 1} & \multicolumn{4}{|c|}{ Session 2} \\
\hline & \multicolumn{2}{|c|}{ No-Mask Condition } & \multicolumn{2}{|c|}{ Mask Condition } & \multicolumn{2}{|c|}{ No-Mask Condition } & \multicolumn{2}{|c|}{ Mask Condition } \\
\hline & $\begin{array}{l}\text { Neutral } \\
\text { Words }\end{array}$ & $\begin{array}{l}\text { Color } \\
\text { Names }\end{array}$ & $\begin{array}{l}\text { Neutral } \\
\text { Words }\end{array}$ & $\begin{array}{l}\text { Color } \\
\text { Names }\end{array}$ & $\begin{array}{l}\text { Neutral } \\
\text { Words }\end{array}$ & $\begin{array}{l}\text { Color } \\
\text { Names }\end{array}$ & $\begin{array}{l}\text { Neutral } \\
\text { Words }\end{array}$ & $\begin{array}{l}\text { Color } \\
\text { Names }\end{array}$ \\
\hline $\begin{array}{l}\text { Colored Plate } \\
\text { (Interference) }\end{array}$ & 29.50 & 33.75 & 39.44 & 48.94 & 26.87 & 30.50 & 35.19 & 37.69 \\
\hline $\begin{array}{l}\text { Achromatic Plate } \\
\text { (Control) }\end{array}$ & 29.75 & 32.69 & 42.94 & 43.31 & 27.00 & 30.37 & 34.81 & 36.19 \\
\hline Difference & -.25 & 1.06 & -3.50 & 5.63 & -.13 & .13 & .38 & 1.50 \\
\hline
\end{tabular}

Glass word-reading portion was that no color-naming conditions existed for the present Ss. A color-naming condition always preceded the crucial conditions of word reading with the interference card in the Gumenik and Glass study. Interference to word reading may have appeared, but this interference might not have been present without the color-naming practice prior to word reading.

$$
\text { SUBJECTS }
$$

Eight males ranging in age from 17 to 21 who had recently completed Army basic training served in the experiment. Visual acuity, with correction if necessary, and color vision were norma!.

\section{Stimulus Materials}

Four $22 \times 18$ in. stimulus charts were constructed, each with 12 rows of seven words. For two of the charts, the words were red, blue, gold, and green, each repeated 21 times. For the other two charts, the words were pin, salt, this, and match, each also repeated 21 times. One of each pair of charts was constructed by applying press-on letters (Prestype Futura Demi $1282-48$ ) in the colors red, blue, gold, and green, to glossy photographic paper backed with cardboard. When the words were color names, only incongruent combinations of words and colors were used with each passible incongruent combination of the four colors and four words repeated 7 times. On the card with colored neutral words, each word appeared equally often in each color except that pin was never in red, salt was never in blue, this was never in gold, and match was never in green. This restriction made a comparable three-color response set for each word, as was the case for the incongruently colored color names. A random order of the 84 colored words was used with the restriction that succeeding words were never repeats, and the same was true for colors. Each of the colored cards was reproduced photographically in achromatic shades and in the same size on glossy photographic paper. Development was controlled so that the range of luminance contrasts of the words against the background was approximately the same as for the colors. The legibility reduction mask consisted of opaque white lines $1 / 4 \mathrm{in}$. wide and separated by $1 / 4$ in., running at an angle of $45 \mathrm{deg}$. This was the same size as the plates of words and, when placed over them, exposed only fragments of the words. With minor differences, the single corresponding word plate and the mask were the same as those used by Gumenik \& Glass (1970). The plates were presented to the seated $S$ on an easel at a distance of about $6 \mathrm{ft}$, with the vertical center of the plate approximately at eye level.

\section{PROCEDURE}

At each of two sessions conducted on succeeding days, $S$ read words in eight different conditions. These eight represented all possible combinations of the two types of words (color vs neutral), achromatic vs chromatic plates, and mask vs no-mask conditions. The order of the eight conditions was completely random, with a Latin-square constraint insuring that each condition appeared in each of the eight positions in a S's sequence across the eight Ss. A different random permutation of the eight was similarly rotated for the second session. Prior to the first session, all plates were shown to the $S$ to familiarize him with the different words and procedures. In addition, instructions were given to read the words as quickly as possible following a verbal "Start" command. E started a stopwatch with this "Start" instruction and stopped it when $S$ finished reading. Reading times were recorded to the nearest $1 / 2$ sec. Following the reading of a plate, it was removed from the easel and feedback was given to $S$ on the reading time. Following a $30-\mathrm{sec}$ interval, a new plate (and mask if appropriate) was presented and the process was repeated until all plates had been read with and without the mask. The same procedure without familiarization was used at the second session.

\section{RESULTS AND DISCUSSION}

The 16 reading times for each of the eight $S s$ were analyzed in a repeated measures analysis of variance with four two-level factors of word type, chromaticity, mask condition, and sessions. The main effect for the mask condition factor was highly significant $[F(1,7)=44.3, p<.001]$, with mean reading time equal to $39.8 \mathrm{sec}$ for the mask condition and $30.1 \mathrm{sec}$ for the no-mask condition. The highly significant main effect for sessions $[F(1,7)=32.9, p<.001]$ represented a change from $37.5 \mathrm{sec}$ to $32.3 \mathrm{sec}$ in mean reading time from Session 1 to Session 2. The word type factor was also highly significant $[F(1,7)=23.2$, $\mathrm{p}<.001]$, with the time to read color names averaging $36.7 \mathrm{sec}$, compared to $33.2 \mathrm{sec}$ for neutral words.

Although no significant main effect appeared for the chromaticity factor, the Chromaticity by Word Type interaction was significant $[F(1,7)=$ $7.32, \mathrm{p}<.05]$, as was Word Type by Chromaticity by Sessions $[F(1,7)=$ 21.6, $\mathrm{p}<.001]$. These interactions, plus the nearly significant Chromaticity by Word Type by Mask Condition interaction $[\mathrm{F}(1,7)=2.92$, $\mathrm{p}<.25]$, are of the most theoretical significance for the present purpose of ascertaining whether colors interfere with word reading or just contribute to reduce;legibility. The data producing these interactions are presented in Table 1. These data support an interference explanation, since reading of color words was slow when they were presented in colored inks compared to when they were presented in shades of gray, while this relationship was reversed for the reading of neutral words. Although mean reading times reflected this relationship with and without the mask at each session, it was particularly strong for the condition with the mask at Session 1. For this particular condition, reading of color words required an average of $5.6 \mathrm{sec}$ longer on the card with words in colors than if did on the card where they were printed in grays, whereas neutral words were actually read $3.5 \mathrm{sec}$ faster, on the average, when they were printed in color than when they were in gray. This 9.1-sec difference represents more than a $20 \%$ increase in the time to read words 
resulting from implicit naming responses to irrelevant colors.

The confirmation of the Gumenik and Glass "reversed interference" claim provided by the present data occurred despite some unspecifiable difference in procedures between their study and this one which resulted in a much smaller reduction in legibility for the present study. The present legibility reduction became even smaller for Session 2, and it appears that the reading "practice" during Session 1 largely overcame the "weakening" of the reading response by the mask. It can be seen in Table 1 that this stronger reading response of Session 2 was much less susceptible to interference from irrelevant colors; this fact provides further evidence for the importance of the relative strength between word-reading and color-naming responses as the determinant of "reversed interference."

The absence of a difference in reading time between the chromatic and achromatic plates in the present study was fortunate for examination of interference effects without the complication of differential legibility between these plates. However, this precluded any test of whether the masking stimulus would cause more legibility reduction for an initially lower legibility condition than it would for a higher legibility condition, as the Crook et al (1949) results would predict. The slight difference in Session 1 between reading times for neutral words in gray and neutral words in color without the mask does appear to be amplified in the mask condition. However, the initial difference averaged only $.25 \mathrm{sec}$ and was too small to reliably indicate the direction of the legibility difference.

This confirmation that interference to word reading is a real phenomenon has relevance for theories of selective attention. Treisman (1969) used the "normal" Stroop interference phenomenon, i.e., interference from irrelevant words to color naming, as evidence for the difficulty or impossibility of focusing attention on one stimulus analyzer and gating another. "Reversed" interference increases the evidence for this position, at least for these particular color and word analyzers, since the reversed interference indicates that attention cannot be focused on words to the complete exclusion of colors, just as it cannot be focused on colors to the exclusion of words. REFERENCES

BLACKWELL, H. R. Contrast thresholds of the human eye. Journal of the Optical Society of America, 1946, 36, 624-643. CROOK, M. N., HARKER, G. S., HOF FMAN, A. C̈., \& KENNEDY, J. L. Studies of the effect of typographical spacing on the legibility of numerals under vibration. USAF, Air Materiel Command. Wright-Patterson Air Force Base, Aero Medical Laboratory, Engineering Division, MCREXD-694-1Q, November 29, 1949.

GUMENIK, W. E., \& GLASS, R. Effects of reducing the readability of the words in the Stroop color-word test. Psychonomic Science, 1970, 20, 247-248.

JENSEN, A. R., \& ROHWER, W. D., JR. The Stroop color-word test: A review. Acta Psychologica, 1966, 25, 36-93.

KLEIN, G. S. Semantic power measured through the interference of words with color-naming. American Joumal of Psy chology, 1964, 77, 576-588.

STR OOP, J. R. Studies of interference in serial verbal reactions. Journal of Experimental Psychology, 1935, 18, 643-662.

TREISMAN, A. M. Strategies and models of selective attention. Psychological Review, $1969,76,282-299$. 